settings, it is important to have available information about lifetime risk for various age ranges for the remainder of life, so that women can be offered advice that is specific to their personal and family circumstances.

\section{ACKNOWLEDGEMENT}

The NSW Breast Cancer Institute receives financial support from the NSW Department of Health.

\section{REFERENCES}

1. Pharoah P, Day N, Duffy S, Easton D, Ponder B. Family history and the risk of breast cancer: a systematic review and meta-analysis. Int J Cancer 1997; 71: 800-9.

2. Quinn M, Allen E. Changes in incidence of and mortality from breast cancer in England and Wales since the introduction of screening. BMJ 1995; 311: 1391-5.

3. Taylor R, Boyages J. Absolute risk of breast cancer for Australian women with a family history. Aust NZ J Surgery 2000; 70: 725-31.

4. Pharoah P, Mackay J. Absolute risk of breast cancer in women at increased risk: a more useful clinical measure than relative risk? The Breast 1998; 7: 255-9.
5. Dupont WD, Plummer WD Jr. Understanding the relationship between relative and absolute risk. Cancer 1996; 77: 2193-9.

6. Taylor R, Rushworth RL. Hysterectomy fractions in NSW, 1971-2006. Aust N Z J Public Health 1998; 22: 759-64.

7. Taylor R, Smith D, Hoyer A, Coates M, McCredie M. Breast Cancer in NSW 1972-91. Sydney: NSW Cancer Council, September 1994.

8. Taylor R. Estimating risk for tobacco-induced mortality from readily available information. Tobacco Control 1993; 2: 18-23.

9. Taylor R. Risks from premature deaths from smoking in 15year-old Australians. Aust J Public Health 1993; 17: 358-64.

10. Armitage P, Berry G. Statistical Methods in Medical Research, 3rd edition. Oxford: Blackwell Scientific Publications, 1994.

11. BreastScreen Queensland State Coordination Unit. Annual statistical report for 1996. Brisbane: Queensland Health, 1998.

12. Hopper JL. Genetic testing: review of the scientific literature. Discussion Paper. Sydney: NHMRC National Breast Cancer Centre, 1995.

13. Day N. Cumulative rate and cumulative risk. In: Muir C, Waterhouse J, Mack T, Powell J, Whelan S (editors). Cancer Incidence in Five Continents, Vol V. IARC Scientific publication, No. 88. Lyon: International Agency for Research on Cancer, 1987; Chapter 10. w

\title{
CANCER IN NSW: INCIDENCE AND MORTALITY 1997
}

\section{Marylon Coates and Elizabeth Tracey \\ NSW Cancer Council}

This article highlights some of the information available from the latest report of cancer incidence and mortality in NSW, ${ }^{1}$ published by the NSW Cancer Council in June 2000. A decrease in cancer mortality was confirmed for both males and females. The incidence rate of prostate cancer fell for the third successive year in 1997. This followed a dramatic increase in rates between 1988 and 1994, and is associated with widespread use of prostate specific antigen testing. Detailed information is provided for the first time for liver cancer and mesothelioma, two less common cancers that have rapidly increasing incidence and mortality rates.

\section{THE 1997 REPORT}

Cancer has been a notifiable disease since January1, 1972. Notifications are provided by patient care institutions and pathology laboratories.

The annual report of cancer incidence and mortality contains:

- numbers and rates

- leading cancers

- most common cancers by age

- childhood cancers

- trends and projections

- information about specific cancers including five-year survival and regional variation

- age-specific tables of incidence and mortality

- appendices describing the Central Cancer Registry, coding practices, demography of NSW, statistics and publications.

\section{MOST COMMON CANCERS}

For 1997, 27,285 new cases of cancer and 11,594 deaths attributed to cancer were registered. Prostate, lung, 
FIGURE 2

ANNUAL CHANGES IN CANCER INCIDENCE RATES FOR MALES AND FEMALES, NSW, 1987 TO 1997

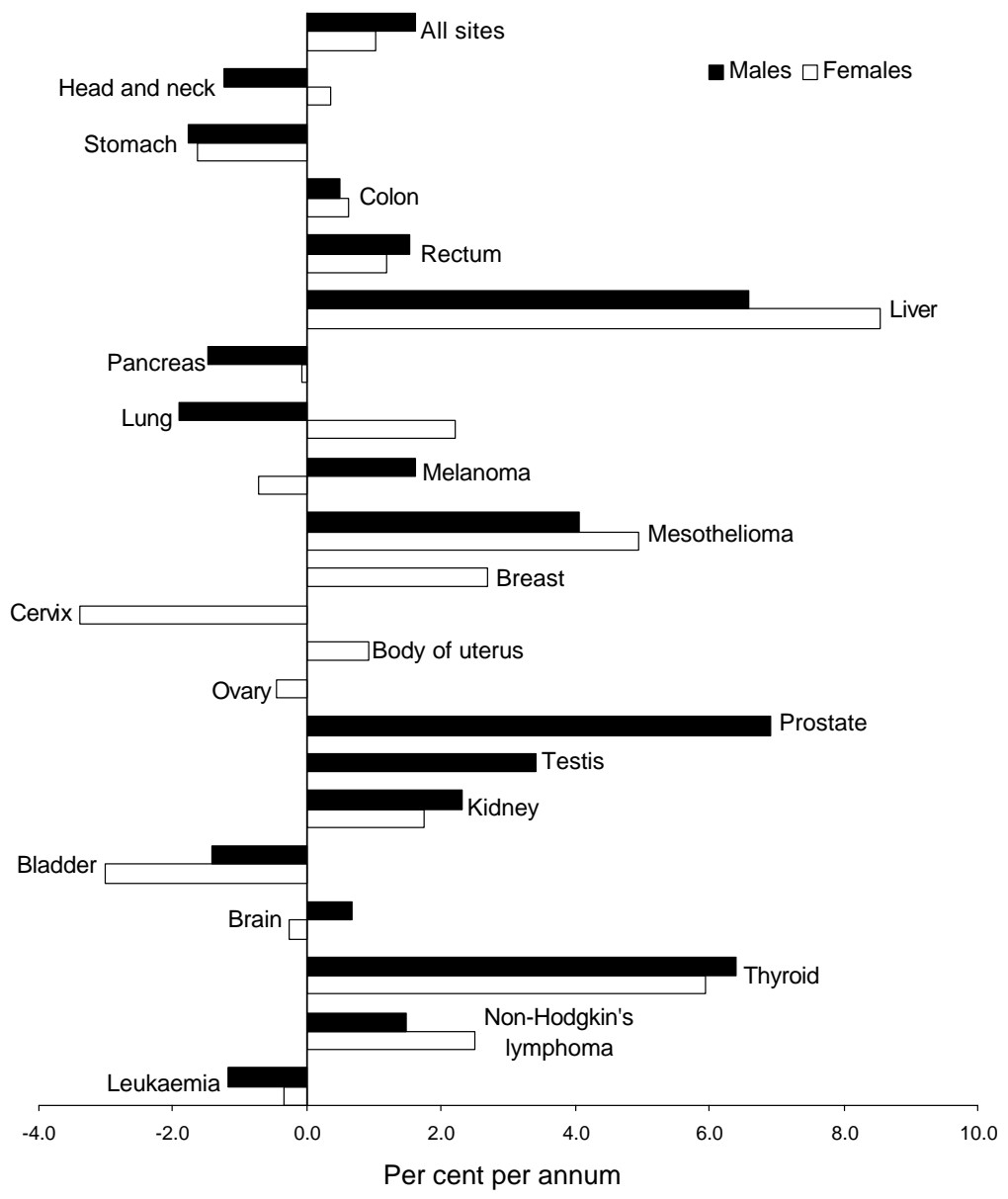

melanoma of skin, colon and rectum were the five most common cancers in males (accounting for 61 per cent of all cancer in males). Cancers of breast, melanoma of skin, colon, lung and rectum were the five most common in females (accounting for 59 per cent of all cancers in females).

\section{TRENDS IN INCIDENCE AND MORTALITY}

Between 1987 and 1997, the incidence rates for cancer of all sites combined rose by 17 per cent for males and 11 per cent for females. The major contributors to this increase were prostate cancer and melanoma in males, and breast and lung cancer and non-Hodgkin's lymphoma in females. Notable trends described in the report included the following:

- incidence rates for prostate cancer fell in 1997 following rapid increases between 1988 and 1994;
- incidence rates continued to fall for cervical cancer, there were fewer than 300 cases in 1997;

- there were falling incidence rates of some of the more common cancers that have low survival rates such as lung cancer, head and neck, and pancreatic cancer in males and stomach and bladder cancer in both males and females;

- the rate of lung cancer in females prior to the age of 50 years is now equal to that of males. Projections indicate that lung cancer rates in males and females will continue to converge with similar rates per 100,000 expected in 2006 (30.8 in males compared to 28.7 in females);

- there was a 16 per cent fall in age standardised mortality rates from breast cancer from 1987-1997;

- the incidence and mortality rates of liver cancer and mesothelioma have increased dramatically 


\section{FIGURE 3}

ANNUAL CHANGES IN CANCER MORTALITY RATES FOR MALES AND FEMALES, NSW, 1987 TO 1997

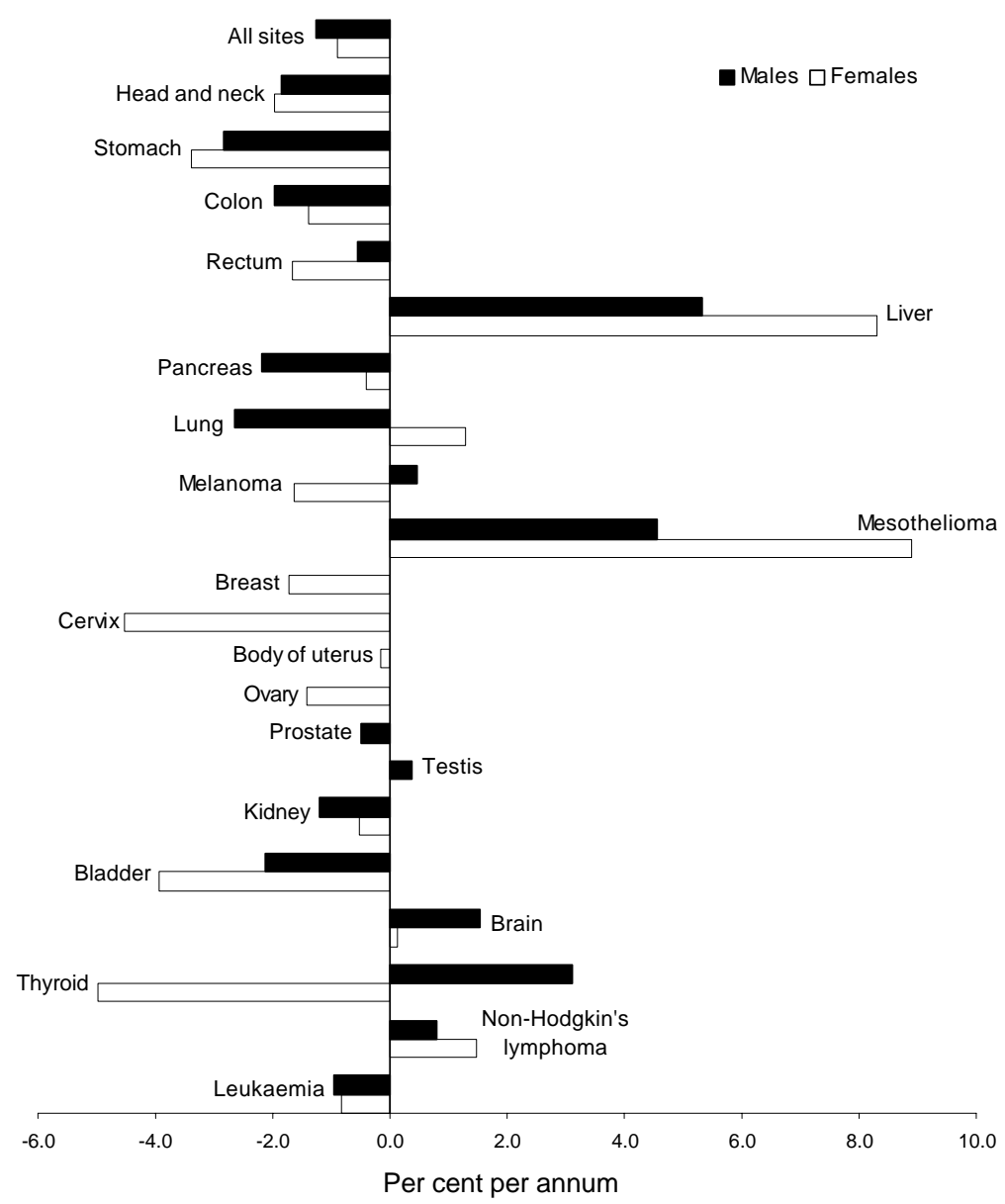

since the early 1970s, and are described in two new feature pages;

- when all cancers are considered together, mortality rates have fallen annually since 1987 by 1.3 per cent in males and 0.9 per cent in females. Age-adjusted mortality in both males and females was the lowest it has been since the Cancer Registry began operation in 1972;

- the large increases in the incidence of cancers of the prostate in males and breast in females have not been reflected in mortality rates;

- changes in mortality from stomach, pancreatic, liver, and lung cancers and mesothelioma are similar to those in incidence.

Figures 2 and 3 show the average annual changes in incidence and mortality from 1987 to 1997.

\section{WEB SITE}

Further information can be found under 'Statistics' on the NSW Cancer Council's Web site at www.cancercouncil.com.au. A printed copy of Cancer in New South Wales: Incidence and Mortality 1997 can be ordered by mail from the NSW Cancer Council, Locked Mail Bag 1, Kings Cross, NSW 1340; or by telephone at (02) 93341902.

\section{REFERENCE}

1. Coates MS, Tracey EA. Cancer in New South Wales: Incidence and Mortality 1997. Sydney: NSW Cancer Council, 2000. 战 